\title{
HIV-Related Stigma and Discrimination Among Health Care Workers During Early Program Decentralization in Indonesia: A Cross-Sectional Study
}

Gaby G. Langi ( $\sim$ gabylangi90@gmail.com )

Field Epidemiology Training Program (FETP), Department of Biostatistics, Epidemiology, and Population Health, Faculty of Medicine, Universitas Gadjah Mada

Arie Rahadi

University Center of Excellence, AIDS Research Center, Health Policy and Social Innovation, Atma Jaya Catholic University of Indonesia Ignatius Praptoraharjo

University Center of Excellence, AIDS Research Center, Health Policy and Social Innovation, Atma Jaya Catholic University of Indonesia

Riris A. Ahmad

Center for Tropical Medicine, Faculty of Medicine, Universitas Gadjah Mada

\section{Research Article}

Keywords: Social Stigma, HIV Infections, Acquired Immunodeficiency Syndrome, Health Facilities, Primary Care, Decentralization, Task-shifting, Indonesia Posted Date: September 15th, 2021

DOI: https://doi.org/10.21203/rs.3.rs-881407/v1

License: @ (i) This work is licensed under a Creative Commons Attribution 4.0 International License. Read Full License 


\section{Abstract \\ Background}

Expanding HIV services by decentralizing provision to primary care raises a possible concern of HIV-related stigma and discrimination (SAD) from health care workers (HCWs) as new service points gain experience in HIV care delivery during early implementation. We surveyed indicators and examined the correlates of SAD among HCWs in a decentralizing district of rural Gunungkidul, Indonesia.

\section{Methods}

We conducted a cross-sectional survey on a random stratified sample of $234 \mathrm{HCWs}$ in 14 public health facilities (one referent hospital, 13 primary health centers [PHC]) during the second year of decentralization roll-out in the district. We computed the prevalence of SAD indicators and used multivariable logistic regression with bootstrap standard errors to estimate the correlates of these indicators controlling for variations across facility units.

\section{Results}

The prevalence of SAD among HCWs was 71\% in fear of HIV transmission when caring for people living with HIV (PLHIV), 75\% in perceived negative image of PLHIV, and tended to differ between hospital and PHC HCWs for avoidance of service duties to HIV key populations (52.5\% vs. $63.8 \% ; p=0.081)$ and discriminatory practices during HIV care delivery $(96.1 \% v s .85 .2 \% ; p=0.008)$. Recent interactions with PLHIV and receipt of training lowered the odds of fear of HIV transmission $(p \leq 0.036)$. However, the odds of avoiding care duties increased with receipt of training $(p<0.001)$ and male sex $(p=0.050)$. Age, HIV knowledge, hospital facility, and non-physician cadres increased the odds of discriminatory practices $(p \leq 0.026)$. No significant correlate was found for perceived negative image of PLHIV.

\section{Conclusion}

HIV-related SAD among HCWs can be prevalent during early decentralization, highlighting the need for timely or preparatory interventions with a focus on building the capacity of hospital and non-physician workforce for positive patient-provider interactions when delivering HIV care.

\section{Background}

Stigma and discrimination (SAD) towards people living with HIV (PLHIV) remains widespread across the globe and particularly in low- and middle-income countries (LMICs) [1]. More than half of residents of LMICs participating in population surveys on SAD were estimated to exhibit at least one HIV-related SAD attitude within their lifetime [2]. A global community-driven monitoring initiative reported an incident of denial of health services for one in every eight PLHIV during their lifetime [3]. In the health care setting, evidence demonstrates that SAD prevents access to HIV testing and diagnosis, disincentivizes uptakes of antiretroviral treatment (ART), erodes treatment adherence, and compromises the quality of life of PLHIV [4-8]. The deleterious consequences of suboptimal health behaviors in morbidity and mortality [9] place health care delivery in a prominent rank among the priority sectors to target for SAD elimination [10].

The global commitment to HIV-related SAD has been recognized on an equal footing with efforts to eliminate new HIV infections and AIDS-related deaths [11]. In 2018, UNAIDS launched a partnership to support countries in protecting the human rights of PLHIV and advance country capacity to reduce SAD [10]. Within the short timespan since the launch, changes to the baseline levels of SAD have been reported in a varying degree, and most countries failed to achieve the elimination target by the end of 2020 [12]. Recent data reveal that the proportions of PLHIV experiencing SAD during health care delivery varied greatly in the range of $1.7-21.0 \%$ [12], which suggests different trajectories in the capacity to reduce SAD that may be specific to the health system in each locality [13].

Much of the early theoretical ground to distinctively capture and measure SAD in numerical indices was derived from the work of Goffman (1963) who laid the foundation of what constitutes stigma in terms of perpetrated actions (to devaluate) and the impact these inflicted on others (the feeling of discredit) [14]. The conceptualization by Link and Phelan (2001) describes the cognitive and attitudinal process of stigma by active labeling of differences and stereotyping and by separating and eventually excluding those stigmatized from a relevant social context, thereby equating stigma with discrimination [15]. More recent theoretical work clarifies the cognitive process of SAD in which stereotyped ideas or imagined contra attitudes condition future discriminatory actions enacted as a response $[16,17]$. Within this framework, SAD is underpinned by principal human faculties that manifest in knowledge or its lack thereof (ignorance), attitude (prejudice), and actions (discrimination) [18]. UNAIDS describes HIV-related SAD as a process of devaluation of PLHIV (or those associated with HIV) on the basis of real or perceived HIV status (or the associated risk behaviors) culminating in discriminatory or unjust treatment [19]. HIV-related SAD permeates beyond PLHIV by virtue of association with underlying risk behaviors that characterize HIV transmission, which negatively impacts the HIV key populations such as people who inject drugs (PWID), men who have sex with men (MSM), and sex workers [20].

Although experiences of SAD by PLHIV in the health care setting are widely documented [12], examination of SAD attitudes and practices among health care workers (HCWs) has received less attention. The expansion of HIV care and treatment in LMICs over the last two decades brought about innovations to redistributing service capacity more evenly in the health system in response to increased demand by decentralizing provision down to primary care and across the ranks of health care cadres [21]. Advances in diagnostic and antiretroviral technologies have simplified and standardized care procedures to the point of becoming amenable to decentralized provision by non-physician clinicians at the primary care level [22]. HIV care decentralization provides a unique programatic context for emergent SAD in which a wider reach of HCWs is introduced firsthand to the care engagement of PLHIV and key populations. 
Investigations into decentralized programming indicate fear of discrimination and unwarranted disclosure of HIV status as two areas of SAD that PLHIV feel strongly concerned about or commonly experienced during health care delivery [23, 24], possibly mirroring the differential quality of care between primary health centers (PHCs), as an emerging model of HIV care provision in the health system, and the referent hospital, which pioneered HIV care in the community. Consequently, some areas of SAD can be viewed as a trade-off outcome with access convenience for a segment of patients who changed their access location to PHCs due to high service volumes at the referent hospital or proximity to care providers within the community. The indication of differential quality of care receives little support in reviews of ART decentralization programs in LMICs, which have concluded non-inferior outcomes of PHCs or other equivalent facilities relative to the pioneering hospital [21, 25-27]. However, the summary effect sizes in these reviews mask the impact of various stages of program maturity in the included studies, with earlier periods more likely exhibiting emergent SAD as new facilities were adapting to the implementation. Similarly, existing studies exploring HIV-related SAD among HCWs are limited in the scope of health care professions or portray mature programs [28-31], which forego the dynamics in patient-provider interactions and emergent SAD during early decentralization.

The current study seeks to illuminate the topic on SAD behaviors in HCWs in a decentralizing rural district of Indonesia, a country that has expanded its HIV care to over 5.000 health care facilities [32]. Herewith we present the findings from a survey of HCWs, describing the prevalence of SAD and examining the correlates of different indicators of HIV-related SAD.

\section{Methods}

\section{Study design and setting}

We conducted a cross-sectional survey in Gunungkidul, a rural district in Yogyakarta Province, with data collection from December 2016 to March 2017 . Two hospitals and 30 PHCs serviced an estimated 700.000 residents of the district in 2016 [33]. In 2016 there were 238 documented HIV cases with most diagnoses occurring in late clinical stages [34]. In response to the growing number of cases, the District Health Office decentralized provision of HIV testing and care from the district hospital to 13 PHCs beginning in 2015. The initiative expanded the role of PHCs to HIV testing, referrals of hospital-based ART initation, management of stable ART patients, and treatment of non-severe opportunistic infections.

\section{Participants and Sample Size}

We surveyed HCWs at the district referent public hospital and $13 \mathrm{PHCs}$ participating in the decentralization program. HCWs were eligible to participate in the survey if they had $\geq 12$ months of service with the current facility in a medical or non-medical area. Health care professions comprised physicians (specialists and general practitioners), dentists, registered nurses, midwives, and a class of health care cadres with limited or no medical duties, including nutritionists, physiotherapists, laboratory or radiology technicians, medical record officers, and public health experts. We powered the survey to detect $64 \%$ HIV-related SAD in a stratified sampling design [35] and recruited $234 \mathrm{HCWs.} \mathrm{We} \mathrm{stratified} \mathrm{recruitment} \mathrm{by} \mathrm{facility} \mathrm{type} \mathrm{and} \mathrm{allocated} \mathrm{recruitment} \mathrm{in} \mathrm{relation} \mathrm{to} \mathrm{the} \mathrm{size} \mathrm{of} \mathrm{HCW}$ populations in the hospital and PHCs. A list of HCWs meeting eligibility in 14 facilities was obtained, and a random proportional sample was selected in each stratum using a standard spreadsheet program.

\section{Study instruments}

The survey questionnaire on SAD indicators was adapted from Measuring HIV Stigma and Discrimination among Health Facility Staff prepared by The Health Policy Project [36]. The questionnaire also had an extended module on SAD in the context of prevention of mother-to-child HIV transmission. Data from this module were not utilized in this study. The main questionnaire was divided into five sections: one for demographic information including HIV knowledge and the remaining for various SAD indicators and in-facility HIV policy environment. The questionnaire has been used in diverse settings [29, 37] and proved simple to administer or for self-administration without much overhead in duration or cognitive effort. In the study setting, we piloted the translated questionnaire in $30 \mathrm{HCWs}$ from the hospital prior to use in survey respondents, which demonstrated satisfactory inter-item reliability (Cronbach's alpha $>0.70$ for all sections). Selected HCWs were contacted to participate in the survey. Interested HCWs then received hardcopy questionnaires, an informed consent form, and survey instructions via courier or delivered in-person by a team member for those who wished to complete the questionnaire on the same day. Respondents self-completed the questionnaire in 20-35 minutes.

\section{Study outcomes and other variables}

Four SAD indicators were constructed from responses in the two sections of the questionnaire eliciting personal opinions on HIV infection control and PLHIV and key populations. SAD indicator 'fear of HIV infection' pertains to levels of worry (from 'not worried' to 'very worried') when performing medical duties with PLHIV patients involving direct contact with the clothing, dressing the wounds, blood drawing, and temperature check. 'Perceived negative image of PLHIV' corresponds to the level of agreement (from 'strongly agree' to 'strongly disagree') with exemplary statements on their perceived disregard for infecting others, presumptive promiscuity, reckless risk behaviors, and whether PLHIV deserve shame and HIV is believed to be a punishment for their risky behaviors. The third SAD indicator was assessed as how respondents would approve (from 'strongly agree' to 'strongly disagree') 'avoidance of service duties' for MSM, PWID, and sex workers, the HIV key populations, if given the opportunity. Lastly, 'discriminatory practices' refer to unjust or excessive precautions ('yes' and 'no') in contact avoidance, double gloving, being gloved up throughout the entire care episode, or use of special infection-control measures that HCWs would not apply when caring for non-HIV patients. All SAD indicators used a four-item Likert scale except for discriminatory practices. HCW cadres with core duties not relevant to one or more task described in a question set for a SAD indicator could select a 'not applicable' option. Fear of HIV infection and discriminatory practices were specific to medical cadres in the health care delivery. All respondents provided responses to the remaning SAD indicators.

We included age, sex, education (< and $\geq$ bachelor's degree), HIV knowledge (scale: 0-10), facility type (hospital and PHCs), HCW cadres (physician, nurse, other professions), interactions with PLHIV, and receipt of training in HIV and SAD topics. HIV knowledge test comprised 10 questions on basic knowledge of HIV transmission and its mode of exposure [38, 39], with a total score accumulated on correct answers. 


\section{Statistical Analysis}

We described sample characteristics in mean and standard deviation for continuous variables and counts and proportion for binary or categorical variables, stratified by facility type. We formed dummy indicators of SAD by dichotomizing all Likert-like responses at the mid category, which are 'worried' and 'very worried' for fear of HIV infection and 'agree' and 'strongly agree' for both perceived negative image and avoidance of service duties. Discriminatory practices were present if the respondent reported any unnecessary preventive measure. Prevalence of SAD indicators was then computed in a similar manner.

Differences by facility type were evaluated using the Student's t-test or Pearson's chi-squared test. As we were concerned that our broad stratification may lead to imbalanced proportions of HCWs sampled across PHCs, we evaluated the effect of these differential sampling rates on SAD prevalence using binomial regression with the logit link function for fractional, prevalence outcomes in the $0-1$ range [40]. Table A1 in the supplement to this article reports no evidence of association between PHC sampling rates and the prevalence estimates on all SAD indicators $(p \geq 0.308)$. Multivariable logistic regression was used to explore correlates of SAD indicators. We removed education from the final model as this variable was deemed redundant in differentiating groups of HCW cadres between phsycians, who all had at least a bachelor's qualitifaction, and others. Accounting for clustered responses within facility units, we calculated the bias-corrected standard error and the corresponding $95 \%$ confidence intervals by re-sampling within strata and over facility units in 10.000 bootstrap replicates for all multivariable analyses [41-42]. We pursued this option as the number of facility units was deemed too few to generate reliable statistics using the conventional method of robust estimation [43]. All $p$-values $<0.050$ were considered to provide sufficient evidence of statistical significance. Stata version 14.2 (College Station, TX) was used for all analyses.

\section{Results}

\section{Characteristics of respondents}

A total of $234 \mathrm{HCWs}$ participated in the survey with an equal proportion of HCWs from the hospital $(n=118)$ and PHCs $(n=116)$. HCWs were on average 40 years old at the time of survey with a female majority, and could answer correctly no more than four questions on basic knowledge of HIV transmission and its mode of exposure (Table 1). PHC HCWs tended to be more highly educated with over $40 \%$ having at least a bachelor's qualification compared to approximately $30 \%$ of their hospital counterparts. A majority were in the nursing or midwifery profession with slightly more physicians and other professions working at PHCs. Significantly more hospital HCWs (63.6\%) than PHC HCWs (44.8\%) had recent interactions with PLHIV ( $p=0.004)$. Most HCWs had yet to receive any training in HIV and SAD, infection control and universal precautions, informed consent and patient confidentiality, or SAD in HIV key populations. All characteristics except recent interactions with PLHIV were broadly similar for HCWs from either facility type.

Table 1. Respondent characteristics by facility type 


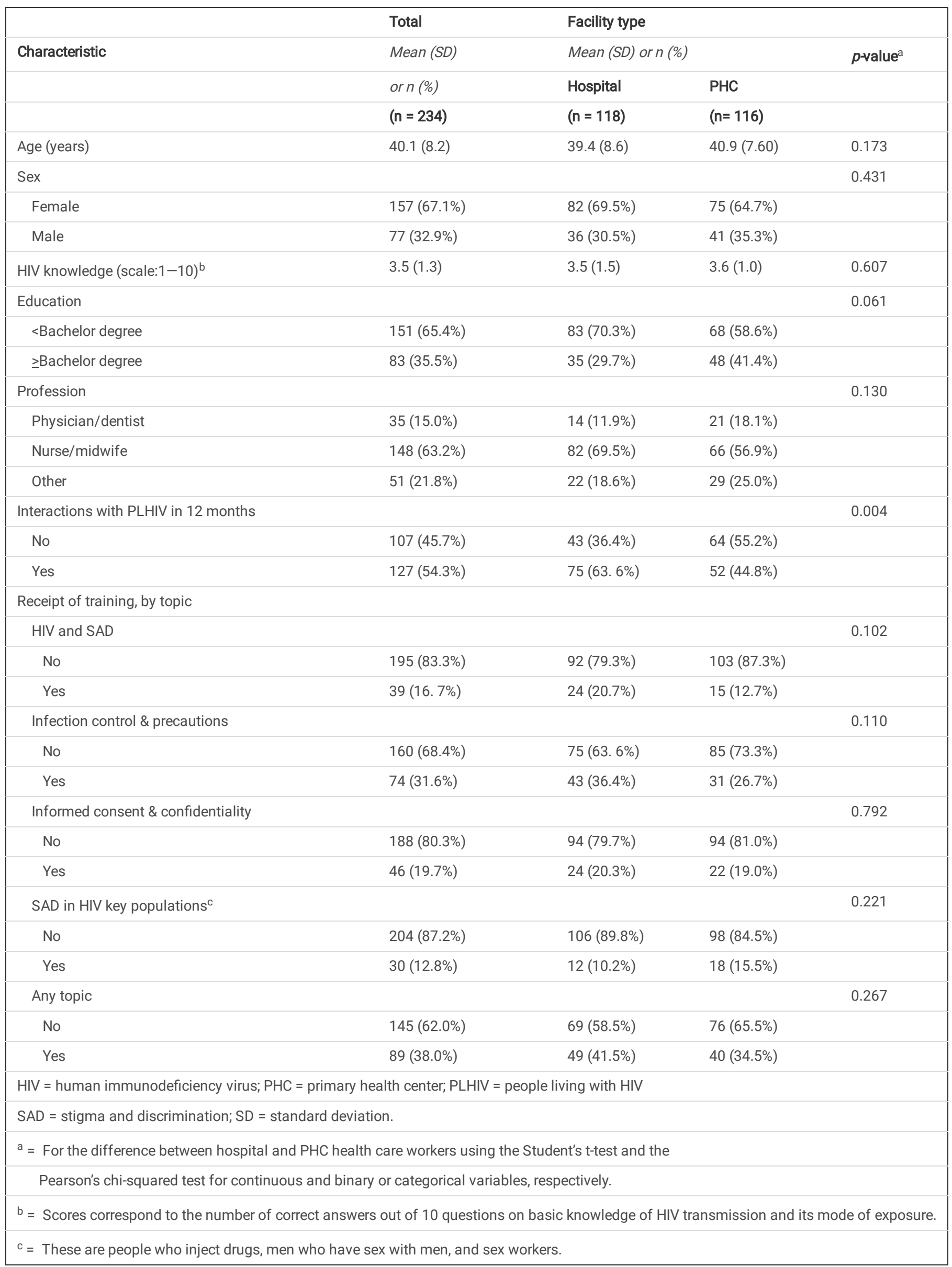


Figure 1 presents the prevalence estimates of perceived HIV-related SAD. Perceived SAD was prevalent, in rates greater than $50 \%$, in all four indicators for both facility types. Of $215 \mathrm{HCWs}$ who were eligible to provide responses, approximately $71 \%$ in both facility types feared contracting HIV infection when caring for PLHIV patients. There was a similarly high prevalence of hospital and PHC HCWs who perceived a negative image of PLHIV ( 75\%) out of all HCWs. Close to $64 \%$ of all PHC HCWs would avoid service duties for HIV key populations if and when it became feasible to do so. The prevalence of this indicator was lower for hospital HCWs $(\sim 53 \%)$, and the difference trended towards significance $(p=0.081)$. Discriminatory practices were the most prevalent SAD indicator, reported by over $80 \%$ of $191 \mathrm{HCW}$ involved in health care delivery, and were significantly higher for hospital HCWs than their PHC counterparts ( 96\% vs. $\sim 85 \% ; p=0.008)$.

\section{Correlates of HIV-related SAD}

Table 2 presents the correlates of HIV-related SAD among HCWs in all four SAD indicators from multivariable analyses. The odds of fear of HIV infection were approximately half as much for HCWs who had recent interactions with PLHIV (adjusted odds ratio [aOR] $=0.45 ; 95 \%$ confidence interval [CI] = 0.28-0.95; $p=$ $0.036)$ and received any training on HIV and $\mathrm{SAD}(\mathrm{aOR}=0.48 ; \mathrm{Cl}=0.29-0.68 ; p<0.001)$. No correlate was found for perceived negative image of PLIV as there was no significant association between any of the characteristics and this SAD indicator. Receipt of training increased the odds of avoiding service duties for HIV key populations by more than two-fold $(\mathrm{aOR}=2.41 ; \mathrm{Cl}=1.73-5.29 ; p<0.001)$. Male sex appeared less likely to avoid service duties relative to their female counterparts with a borderline significant association $(\mathrm{aOR}=0.72 ; \mathrm{Cl}=0.21-1.00 ; p=0.050)$. The odds of discriminatory practices increased with older age $(\mathrm{aOR}=1.08 ; \mathrm{Cl}=1.01-1.22 ; p=0.016)$, HIV knowledge $(\mathrm{aOR}=2.26 ; \mathrm{Cl}=1.45-2.97 ; p<0.001)$, and for hospital HCWs $(\mathrm{aOR}=5.13 ; \mathrm{Cl}=1.82-10.98 ; p=0.001)$ or non-physician cadres, including nurses $/$ midwives $(\mathrm{aOR}=7.23 ; \mathrm{Cl}=1.63-26.34 ; p=0.005)$ and other professions $(\mathrm{aOR}=4.51 ; \mathrm{Cl}=1.18-15.88 ; p=0.026)$.

Table 2. Correlates of HIV-related stigma and discrimination 
Fear of HIV

\begin{tabular}{|c|c|c|c|c|c|c|c|c|c|c|c|c|}
\hline \multirow{4}{*}{ Characteristic } & \multicolumn{3}{|c|}{ Fear of HIV } & \multicolumn{3}{|c|}{ Perceived negative } & \multicolumn{3}{|c|}{ Avoidance of service } & \multicolumn{3}{|c|}{ Discriminatory } \\
\hline & \multicolumn{3}{|c|}{ infection $^{a}$} & \multicolumn{3}{|c|}{ Image of PLHIV ${ }^{a}$} & \multicolumn{3}{|c|}{ Duties $^{a}$} & \multicolumn{3}{|c|}{ practice $^{a}$} \\
\hline & \multicolumn{3}{|c|}{$(n=215)$} & \multicolumn{3}{|c|}{$(n=234)$} & \multicolumn{3}{|c|}{$(n=234)$} & \multicolumn{3}{|c|}{$(n=191)$} \\
\hline & $\mathrm{aOR}$ & $95 \% \mathrm{Cl}^{\mathrm{b}}$ & $\begin{array}{l}p- \\
\text { value }^{b}\end{array}$ & $\mathrm{aOR}$ & $95 \% \mathrm{Cl}^{\mathrm{b}}$ & $\begin{array}{l}p- \\
\text { value }^{\mathrm{b}}\end{array}$ & $\mathrm{aOR}$ & $95 \% \mathrm{Cl}^{\mathrm{b}}$ & $\begin{array}{l}p- \\
\text { value }^{b}\end{array}$ & $\mathrm{aOR}$ & $95 \% \mathrm{Cl}^{\mathrm{b}}$ & $\begin{array}{l}p- \\
\text { value }^{\mathrm{b}}\end{array}$ \\
\hline Age & 1.02 & $\begin{array}{l}0.98- \\
1.04\end{array}$ & 0.497 & 1.01 & $\begin{array}{l}0.99- \\
1.04\end{array}$ & 0.195 & 0.99 & $\begin{array}{l}0.96- \\
1.08\end{array}$ & 0.635 & 1.08 & $\begin{array}{l}1.01- \\
1.22\end{array}$ & 0.016 \\
\hline Sex (male) & 0.78 & $\begin{array}{l}0.53- \\
1.77\end{array}$ & 0.767 & 1.55 & $\begin{array}{l}0.99- \\
2.00\end{array}$ & 0.055 & 0.72 & $\begin{array}{l}0.21- \\
1.00\end{array}$ & 0.050 & 0.30 & $\begin{array}{l}0.06- \\
1.41\end{array}$ & 0.138 \\
\hline HIV knowledge ${ }^{c}$ & 0.99 & $\begin{array}{l}0.77- \\
1.93\end{array}$ & 0.518 & 0.95 & $\begin{array}{l}0.87- \\
1.13\end{array}$ & 0.729 & 1.07 & $\begin{array}{l}0.54- \\
1.15\end{array}$ & 0.572 & 2.26 & $\begin{array}{l}1.45- \\
2.97\end{array}$ & $<0.001$ \\
\hline $\begin{array}{l}\text { Facility type } \\
\text { (hospital) }\end{array}$ & 1.12 & $\begin{array}{l}0.73- \\
1.59\end{array}$ & 0.592 & 0.99 & $\begin{array}{l}0.57- \\
1.61\end{array}$ & 1.000 & 0.54 & $\begin{array}{l}0.23- \\
1.02\end{array}$ & 0.055 & 5.13 & $\begin{array}{l}1.82- \\
10.98\end{array}$ & 0.002 \\
\hline \multicolumn{13}{|l|}{ Profession } \\
\hline Physician/dentist & \multicolumn{3}{|c|}{ Reference } & \multicolumn{3}{|c|}{ Reference } & \multicolumn{3}{|c|}{ Reference } & \multicolumn{3}{|c|}{ Reference } \\
\hline Nurse/midwife & 2.31 & $\begin{array}{l}0.85- \\
4.44\end{array}$ & 0.109 & 1.59 & $\begin{array}{l}0.69- \\
2.32\end{array}$ & 0.395 & 1.05 & $\begin{array}{l}0.24- \\
1.85\end{array}$ & 0.895 & 7.23 & $\begin{array}{l}1.63- \\
26.34\end{array}$ & 0.005 \\
\hline Others $^{d}$ & 1.34 & $\begin{array}{l}0.62- \\
2.48\end{array}$ & 0.540 & 2.00 & $\begin{array}{l}0.73- \\
3.58\end{array}$ & 0.216 & 1.51 & $\begin{array}{l}0.25- \\
2.91\end{array}$ & 0.589 & 4.51 & $\begin{array}{l}1.18- \\
15.88\end{array}$ & 0.026 \\
\hline $\begin{array}{l}\text { Interactions with } \\
\text { PLHIV }\end{array}$ & 0.45 & $\begin{array}{l}0.28- \\
0.95\end{array}$ & 0.036 & 1.01 & $\begin{array}{l}0.68- \\
1.28\end{array}$ & 1.000 & 1.32 & $\begin{array}{l}0.34- \\
2.01\end{array}$ & 0.516 & 0.47 & $\begin{array}{l}0.19- \\
1.43\end{array}$ & 0.285 \\
\hline \multicolumn{13}{|l|}{$\begin{array}{l}\text { in } 12 \text { months } \\
\text { (yes) }\end{array}$} \\
\hline $\begin{array}{l}\text { Receipt of any } \\
\text { training }\end{array}$ & 0.48 & $\begin{array}{l}0.29- \\
0.68\end{array}$ & $<0.001$ & 0.88 & $\begin{array}{l}0.54- \\
1.20\end{array}$ & 0.299 & 2.41 & $\begin{array}{l}1.73- \\
5.29\end{array}$ & $<0.001$ & 0.76 & $\begin{array}{l}0.26- \\
12.57\end{array}$ & 0.643 \\
\hline
\end{tabular}

$(\text { yes) })^{\mathrm{e}}$

aOR = adjusted odds ratio; $\mathrm{Cl}$ = confidence interval; HIV = human immunodeficiency virus; PLHIV = people living with HIV.

$\mathrm{a}=$ Fear of infection: how worry staff are with the prospect of HIV transmission when caring for PLHIV; perceived negative image of PLHIV: unfounded beliefs, presumptions of negative behaviors of PLHIV; avoidance of service duties: ommission, neglect to provide services for HIV key populations if such an option becomes feasible; discriminatory practice: unnecessary preventive measures taken when caring for PLHIV.

$\mathrm{b}=$ Confidence intervals and $p$-values from bias-corrected standard errors estimated from 10.000 bootstrap replicates.

${ }^{c}=$ Measured using 10 questions on basic knowledge of HIV transmission and its mode of exposure.

$\mathrm{d}=$ A class of cadres with limited or no medical duties, including nutritionists, physiotherapists, laboratory or radiology technicians, medical record officers and public health experts.

$\mathrm{e}=$ Training covers one or more of the following topics: HIV and stigma and discrimination; infection control and universal precautions; informed consent and patient confidentiality; and stigma and discrimination in HIV key populations.

\section{Discussion}

The prevalence of SAD during early decentralization was high as found in this setting and in equivalently concerning levels for all the four indicators despite some notable differences between hospital and PHC HCWs. Highly prevalent discriminatory practices, exceeding $90 \%$ and $80 \%$ of $\mathrm{HCWs}$ at the referent hospital and PHCs respectively, may indicate a lack of understanding of infection control, as evidenced from the low training coverage and suboptimal knowledge scores. Different areas of SAD seem to have unique correlates in the type and direction of effect. Systemic correlates encapsulating individual HCWs within their workplace or health care professions exert a greater likelihood of SAD than do demographic correlates or those related to competency such as training, HIV knowledge, and service interactions.

A rather unusual finding is related to how training can have an opposing influence on certain SAD indicators. In this case, training was associated with a reduction in the odds of fear of infection and unexpectedly increased avoidance of service duties. Our liberal definition of training as any receipt in one or more competency topic may misrepresent the training effect in its association with service avoidance. We defined training as such since some of the training topics may broadly correspond to more than one SAD indicator. This approach could, however, underplay specific trainings that are more relevant to service avoidance and result in a statistical artifact for other SAD indicators that share little in construct with fear of infection.

The perverse association of HIV knowledge with discriminatory practices contrasts with prior studies [44-45] and deserves further attention. The low HIV knowledge scores with a narrow spread in this study population suggests knowledge levels that are yet sufficient to instill a proper comprehension of HIV transmission and how this can be prevented safely and emphatically during health care interactions with PLHIV. No other SAD indicators were correlated with 
HIV knowledge. Improving knowledge is essential and needs be recognized as one of the factors that condition or mediate SAD-preventive behaviors as found in other studies of HCWs or other populations in LMICs [46-47].

Discriminatory practices are more prevalent in the hospital and among the non-physcian cadres. HIV patients seeking care at the hospital tend to be in late clinical stages and have a worse prognosis, requiring more invasive procedures that may subject ill-informed HCWs to excessive prevention in the presence of a perceived elevated threat of HIV and opportunistic infections. As decentralization program matures, more burden of acute care will be alleviated through expanded health system capacity to diagnose and enroll a greater number of PLHIV into ART care at PHCs [48-50], and this growth in implementation can be expected to indirectly reduce the excess SAD of hospital HCWs. SAD in non-physician cadres can be attributed to the physician-centered model of care preceding decentralization that placed nurses or other medical professions in support roles, with a limited functional scope in the delivery of vital health care for PLHIV such as management of opportunistic infections or ART prescribing. Decentralization taps into the supply of non-physician cadres and empowers them to assume clinical leadership in HIV care with documented success in other LMICs [25-26]. Quasi-experimental evidence demonstrates SAD reduction among nurses after participation in health delivery leadership programs [51].

Given the high prevalence of SAD among HCWs in this early decentralization setting, capacity building activities to combat SAD can are needed. Among the top priorities is special trainings on HIV-related SAD with a hands-on approach to nurture effective service interactions that uphold the rights and dignity of PLHIV and HIV key populations. A review of the existing national curricula, which HCWs must complete to hold a professional certification in HIV care, can identify gaps in modules, program structures, and learning methodologies to better adapt to the needs of PLHIV and HIV key populations and to the demand of decentralized programs in clinical leadership roles for nurses and other relevant non-physician cadres. Engagement with PLHIV groups as experts in the review process, content updating, and training facilitation will ensure that curricula stay abreast of emerging community perspectives.

Current approaches to capacity building allow piecemeal deliveries where a curriculum or a competency program is completed on standalone topics accumulated over a period of time. While offering flexibility, these approaches can delay completion of essential skills and result in partial competence. Systematizing training deliveries coherently for a comprehensive coverage of topics is another area of improvement in capacity building. Preferably, all essential trainings should be completed prior to or at the earliest time around the decentralization program roll-out for all HCW cadres.

Our findings should be interpreted with caution. Apart from the artifactual problem described above, the training effect on SAD can also be an outcome of selfselection where the trainings attracted participation from HCWs with persistent discriminatory attitudes or those who reasonably protect themselves from nosocomial HIV transmission rather than vice versa due to the cross-sectional design. Secondly, two SAD indicators depicted in this study, namely perceived negative image and avoidance of service duties, evaluate perceptions and hypothetical (in)actions which may or may not bear resemblance to the actual behavior of HCWs and therefore should not be construed as a definite form of enacted SAD. Thirdly, we do not feel that social desirability drove our results given the prevalent SAD found in the study and the self-administration of the survey, which minimized the likelihood of responses being falsely congruent with the expectations of the research team. Lastly, our survey participants encompassed a wider pool of health care cadres, with some non-medical professions having minimal exposure to HIV and thereby elevating the SAD prevalence as compared to what would be expected if participation was limited to medical professions.

Program implementation in high-SAD environment such as the study setting can benefit from the development and evaluation of innovations in capacity building of HCWs to reduce SAD. Tracking of SAD indicators over time can give insights into how SAD evolves through phases of program maturity and impacts on long-term patient outcomes.

\section{Conclusion}

Early decentralization is a critical period with possible high SAD in service delivery as a broad spectrum of HCW cadres participate in rapidly expanding services to anticipate the surging demand for HIV care. Facility type in which HCWs provide services and types of HCW cadres, and to a lesser extent HIV knowledge and training, are the strongest correlates of SAD. Pre-decentralization preparatory work or timely interventions in capacity building, emphasizing competencies to create safe and emphatic interactions during health care delivery, can reduce SAD among HCWs going forward.

\section{List Of Abbreviations}

$\mathrm{aOR}$

Adjusted odd ratio; ART:Antiretroviral treatment; Cl:Confidence interval; HCWs:Health care workers; HIV:Human immunodeficiency virus; LMICs:Low-and middle-income countries; MSM:men who have sex with men; PHCs:Primary health centers; PLHIV:people living with HIV; PWID:people who inject drugs; SAD:Stigma and discrimination.

\section{Declarations}

\section{Ethics approval and consent to participate}

Written informed consent was sought from all respondents. Each respondent received a small souvenir for their participation in the survey. This study protocol received approval from Medical and Health Research Ethics Committee (MHREC) Faculty of Medicine Gadjah Mada University - DR. Sardjito General Hospital (Ref: KE/FK/350/EC/2016) and clearance permits from all participating facilities.

\section{Consent for publication}

Not applicable. 


\section{Availability of data and materials}

The datasets used and/or analysed during the current study are available from the corresponding author on reasonable request.

\section{Competing interests}

The authors declare that they have no competing interests

\section{Funding}

This study was funded by Indonesian Endowment Fund for Education (LPDP), Ministry of Finance of the Republic of Indonesia.

\section{Authors' contributions}

GGL, IP, and RAA were responsible for the initial conception of the research questions and research design. AR contributed to develop the research question and the analyses data plan. AR and GGL conducted the statistical analyses, interpreted the data and wrote the paper. All author contributed to critical revisions and approved the final version of the article.

\section{Acknowledgements}

We acknowledge the following persons and institutes who contributed to this study: health care workers in Wonosari Public Hospital and 13 public health centers who participated in the survey, Gunungkidul District Health Office, and the Field Epidemiology Training Program of Gadjah Mada University.

\section{Authors' information (optional)}

GGL: She has Master of Public Health from Universitas Gadjah Mada, Yogyakarta, Indonesia, now she is a researcher at University Center of Excellence, AIDS Research Center, Health Policy and Social Innovation, Atma Jaya Catholic University of Indonesia.

AR: He has Ph.D in public health from the University of Melbourne, Australia. Now, He is a senior researcher at University Center of Excellence, AIDS Research Center, Health Policy and Social Innovation, Atma Jaya Catholic University of Indonesia.

IP: He has Ph.D in public health from University of Illinois Chicago, USA. Now, He is a senior researcher at University Center of Excellence, Aids Research Center, Health Policy and Social Innovation, Universitas Katolik Indonesia Atma Jaya.

RAA: He has Ph.D in epidemiology and public health from Erasmus University Rotterdam, Netherlands. Now, He is the director of Center for Tropical Medicine, Faculty of Medicine, Universitas Gadjah Mada.

\section{References}

1. UNAIDS. Seizing the moment: tackling entrenched inequalities to end epidemics (Global AIDS update 2020). 2020. https://reliefweb.int/sites/reliefweb.int/files/resources/Global\%20AIDS\%20Update\%202020\%20-\%20Seizing\%20the\%20moment\%20\%20Tackling\%20entrenched\%20inequalities\%20to\%20end\%20epidemics.pdf. Accessed 21 Mar 2021.

2. UNAIDS. On the fast-track to end AIDS by 2030: focus on location and population. 2015. https://www.unaids.org/en/resources/documents/2015/FocusLocationPopulation. Accessed 21 Mar 2021.

3. UNAIDS. Make some noise for zero discrimination: zero discrimination day 1 march 2017. 2017. https://www.unaids.org/sites/default/files/media_asset/2017-zero-discrimination-day_en.pdf. Accessed 22 Mar 2021.

4. Gesesew HA, Tesfay Gebremedhin A, Demissie TD, et al. Significant association between perceived HIV related stigma and late presentation for HIV/AIDS care in low and middle-income countries: a systematic review and meta-analysis. PLoS One. 2017; 12(3): e0173928. https://doi.org/10.1371/journal.pone.0173928. Accessed 23 Mar 2021.

5. Katz IT, Ryu AE, Onuegbu AG, Psaros C, Weiser SD, Bangsberg DR et al. Impact of HIV-related stigma on treatment adherence: systematic review and metasynthesis. J Int AIDS Soc. 2013;16(Suppl 2): 18640. https://doi.org/10.7448/IAS.16.3.18640. Accessed 23 Mar 2021.

6. GNP+, ICW Global, IPPF, UNAIDS. People living with HIV stigma index: asia pacific regional analysis. 2011. https://www.unaids.org/sites/default/files/media_asset/20110829_PLHIVStigmalndex_en_0.pdf. Accessed 18 Mar 2021.

7. Demeke HB. Relationships between HIV-related stigma, coping, social support and health-related quality of life in people living with HIV/AIDS [dissertation]. Emory University; 2013.

8. Holzemer WL, Human S, Arudo J, Rosa ME, Hamilton MJ, Corless I, et al. Exploring HIV stigma and quality of life for persons living with HIV infection. J Assoc Nurses AIDS Care. 2009;20(3):161-8. https://doi.org/10.1016/j.jana.2009.02.002. Accessed 22 Mar 2021.

9. Danforth K, Granich R, Wiedeman D, Baxi S, Padian N. Global mortality and morbidity of HIV/AIDS. In: Holmes KK, Bertozzi S, Bloom BR, Jha P, editors. Major infectious diseases. 3rd ed. Washington, DC: The International Bank for Reconstruction and Development / The World Bank; 2017. p. $29-44$.

10. UNAIDS. Global partnership for action to eliminate all forms of HIV-related stigma and discrimination. 2018. https://www.unaids.org/en/resources/documents/2018/global partnership-hiv-stigma-discrimination. Accessed 23 Mar 2021.

11. UNAIDS. Getting to zero: 2011-2015 strategy. 2010. https://unaidstest.unaids.org/sites/default/files/unaids/contentassets/documents/unaidspublication/2010/20101221_JC2034E_UNAIDS-Strategy_en.pdf. Accessed 
10 Apr 2021.

12. UNAIDS. UNAIDS data 2020. 2020. https://www.unaids.org/sites/default/files/media_asset/2020_aids-data-book_en.pdf. Accessed 10 Apr 2021.

13. UNAIDS. Implementation of the HIV prevention 2020 road map, Nov 2020. 2020. https://www.unaids.org/sites/default/files/media_asset/fourth-annualprogress-report-global-hiv-prevention-coalition_en.pdf. Accessed 10 Apr 2021.

14. Goffman E. Stigma: Notes on the management of spoiled identity. New York: Simon and Schuster; 1963.

15. Link BG, Phelan JC. Conceptualizing stigma. Annu Rev Sociol. 2001;27(1):363-85.

16. Lubkin IM, Larsen PD. Chronic illness: impact and intervention. $8^{\text {th }}$ edition. Burlington: Jones \& Bartlett Learning; 2013.

17. Deacon H, Stephney I, Prosalendis S. Understanding HIV/AIDS stigma: a theoretical and methodological analysis. Cape Town: HSRC Press; 2005.

18. Thornicroft G, Rose D, Kassam A, Sartorius N. Stigma: ignorance, prejudice or discrimination? Br J Psychiatry. 2007;190(3):192-3.

19. UNAIDS. Fact sheet: stigma and discrimination. Joint United Nations Programme on HIV/AIDS, 2003 Dec.

2003. https://data.unaids.org/publications/fact-sheets03/fs_stigma_discrimination_en.pdf. Accessed 24 Mar 2021.

20. Aggleton P, Wood K, Malcolm A. HIV-related stigma, discrimination and human rights violations: case studies of successful programmes. 2005. https://data.unaids.org/publications/irc-pub06/jc999-humrightsviol_en.pdf. Accessed 26 Mar 2021.

21. Kredo T, Ford N, Adeniyi FB, Garner P. Decentralising HIV treatment in lower- and middle-income countries. Cochrane Database Syst Rev. 2013 Jun 27; (6):CD009987. doi: 10.1002/14651858.CD009987.pub2. https://pubmed.ncbi.nlm.nih.gov/23807693/. Accessed 10 Apr 2021.

22. Mazzola LT, Pérez-Casas C. HIV/AIDS diagnostics technology landscape 5th edition. 2015. http://www.unitaid.org/assets/UNITAID_HIV_Nov_2015_Dx_Landscape-1.pdf. Accessed 10 Apr 2021.

23. Onwujekwe O, Chikezie I, Mbachu C, Chiegil R., Torpey K, Uzochukwu B. Investigating client perception and attitude to decentralization of HIV/AIDS treatment services to primary health centres in three Nigerian states. Health Expect. 2016;19(5):111120. https://onlinelibrary.wiley.com/doi/pdfdirect/10.1111/hex.12403. Accessed 11 Apr 2021.

24. Zhang X, Miège P, Zhang Y. Decentralization of the provision of health services to people living with HIV/AIDS in rural China: the case of three counties. Health Res Policy Syst. 2011; doi:10.1186/1478-4505-9-9. https://link.springer.com/article/10.1186/1478-4505-9-9. Accessed 11 Apr 2021

25. Mdege ND, Chindove S, Ali S. The effectiveness and cost implications of task-shifting in the delivery of antiretroviral therapy to HIV-infected patients: a systematic review. Health Policy Plan. 2013 May;28(3):223-36. doi: 10.1093/heapol/czs058. Epub 2012 Jun

26. https://pubmed.ncbi.nlm.nih.gov/22738755/. Accessed 11 Apr 2021

26. Kredo T, Adeniyi FB, Bateganya M, Pienaar ED. Task shifting from doctors to non-doctors for initiation and maintenance of antiretroviral therapy. Cochrane Database Syst Rev. 2014;(7):CD007331. https://pubmed.ncbi.nlm.nih.gov/24980859/. Accessed 11 Apr 2021

27. Suthar AB, Rutherford GW, Horvath T, Doherty M, Negussie EK. Improving antiretroviral scale-up and effectiveness through service integration and decentralization. AIDS. 2014; 28 Suppl 2:S175

85. http://catalogue.safaids.net/sites/default/files/publications/Improving\%20Antiretroviral\%20Therapy\%20Scale\%20Up\%20and\%20Effectiveness.pdf. A 12 Apr 2021

28. Vorasane S, Jimba M, Kikuchi K, Yasuoka J, Nanishi K, Durham J, Sychareun V. An investigation of stigmatizing attitudes towards people living with HIV/AIDS by doctors and nurses in Vientiane, Lao PDR. BMC Health Serv Res. 2017;17:125. https://link.springer.com/article/10.1186/s12913-017-2068-8. Accessed 12 Apr 2021

29. Dawson-Amoah CG. Determinants of HIV stigma among healthcare workers in Ghana [dissertation]. Walden University; 2015. https://scholarworks.waldenu.edu/cgi/viewcontent.cgi?article=2530\&context=dissertations. Accessed 13 Apr 2021.

30. Waluyo A, Culbert GJ, Levy J, Norr KF. Understanding HIV-related stigma among Indonesian nurses. J Assoc Nurses AIDS Care. 2015;26(1):6980. https://www.ncbi.nlm.nih.gov/pmc/articles/PMC4519004/. Accessed 13 Apr 2021.

31. Stringer KL, Turan B, McCormick L, Durojaiye M, Nyblade L, Kempf MC, et al. HIV-related stigma among healthcare providers in the deep south. AIDS Behav. 2016;20(1):115-25. https://www.ncbi.nlm.nih.gov/pmc/articles/PMC4718797/. Accessed 14 Apr 2021.

32. Health Research and Development Agency. Health facility research report 2019. Jakarta: The Ministry of Health Republic of Indonesia; 2019.

33. Central Bureau of Statistics. Population size by age group and sex in Gunungkidul district. 2017. https://gunungkidulkab.bps.go.id/statictable/2017/08/03/60/jumlah-penduduk-menurut-golongan-umur-dan-jenis-kelamin-di-kabupaten-gunungkidul2016.html. Accessed 12 Apr 2021.

34. Gunungkidul Health Office. Health profile of gunungkidul district 2015. Gunungkidul: Gunungkidul Health Office; 2016.

35. Pratikno, H. Stigma and discrimination against PLHIV (people living with HIV AIDS) in Bengkalis District, Riau Province [thesis]. Gadjah Mada University; 2008

36. The Health Policy Project. Measuring HIV stigma and discrimination among health facility staff: standardized brief questionnaire. 2013. https://www.healthpolicyproject.com/pubs/49_StandardizedBriefQuestionnaireMeasuringSD.pdf. Accessed 10 Mar 2021.

37. Risal A, Irwan AM, Sjattar EL. Stigma towards people living with HIV/AIDS among counseling officers in South Sulawesi, Indonesia. Belitung Nurs J. 2018;4(6):552-8. https://belitungraya.org/BRP/index.php/bnj/article/view/543/pdf. Accessed 14 Apr 2021.

38. The Ministry of Health Republic of Indonesia. Basic Health Research 2010: a report. Jakarta: Health Research and Development Agency; 2010.

39. Health Policy Initiative, Task Order 1. Measuring the degree of HIV-related stigma and discrimination in health facilities and providers: working report; Washington, DC: Futures; 2010. 
40. Williams, R. Analyzing proportions: fractional response and zero one inflated beta

models. 2019. https://www3.nd.edu/ rwilliam/stats3/fractionalresponsemodels.pdf. Accessed 26 Feb 2021.

41. Efron, B. Better bootstrap confidence intervals. J Am Stat Assoc. 1987;82(397):171-85. https://www.jstor.org/stable/2289144? seq=1. Accessed 16 May 2021.

42. Muthen B, Asparouhov T. Bootstrap p-value computation. 2021. http://www.statmodel.com/download/FAQ-Bootstrap\%20-\%20Pvalue.pdf. Accessed 15 May 2021.

43. Cameron AC, Miller DL. A practitioner's guide to cluster-robust inference. 2015. http://cameron.econ.ucdavis.edu/research/Cameron_Miller_JHR_2015_February.pdf. Accessed 15 May 2021.

44. Harapan H, Feramuhawan S, Kurniawan H, Anwar S, Andalas M, Hossain MB. HIV-related stigma and discrimination: a study of health care workers in Banda Aceh, Indonesia. Med J Indones. 2013;22(1):22-9. https://doi.org/10.13181/mji.v22i1.518. Accessed 15 May 2021.

45. Feyissa GT, Abebe L, Girma E, Woldie M. Stigma and discrimination against people living with HIV by healthcare providers, Southwest Ethiopia. BMC Public Health. 2012;12:522. https://link.springer.com/article/10.1186/1471-2458-12-522. Accessed 15 May 2021.

46. Li L, Wu Z, Wu S, Zhaoc Y, Jia M, Yan Z. HIV-related stigma in health care settings: a survey of service providers in China. AIDS Patient Care STDs. 2007;21(10):753-62. https://www.ncbi.nIm.nih.gov/pmc/articles/PMC2795451/. Accessed 15 May 2021.

47. Yang H, Li X, Stanton B, Fang X, Lin D, Naar-King S. HIV-related knowledge, stigma, and willingness to disclose: a mediation analysis. AIDS care. 2006;18(7):717-24. https://www.ncbi.nlm.nih.gov/pmc/articles/PMC1933389/. Accessed 15 May 2021.

48. Mutevedzi PC, Lessells RJ, Heller T, Bärnighausen T, Cooke GS, Newell ML. Scale-up of a decentralized HIV treatment programme in rural KwaZulu-Natal, South Africa: does rapid expansion affect patient outcomes? Bull World Health Organ. 2010;88(8):593600. https://apps.who.int/iris/handle/10665/270740. Accessed 16 May 2021.

49. Reidy WJ, Sheriff M, Wang C, Hawken M, Koech E, Elul B, et al. Decentralization of HIV care and treatment services in Central Province, Kenya. J Acquir Immune Defic Syndr. 2014;67(1):e34-40. doi:10.1097/QAl.0000000000000264. https://www.ncbi.nlm.nih.gov/pmc/articles/PMC5108298/. Accessed 16 May 2021.

50. Bilinski A, Birru E, Peckarsky M, Herce M, Kalanga N, Neumann C, et al. Distance to care, enrollment and loss to follow-up of HIV patients during decentralization of antiretroviral therapy in Neno District, Malawi: A retrospective cohort study. PloS one. 2017;12(10):e0185699. https://doi.org/10.1371/journal.pone.0185699. Accessed 16 May 2021.

51. Edwards N, Kaseje D, Kahwa E, Klopper HC, Mill J, Webber J, et al. The impact of leadership hubs on the uptake of evidence-informed nursing practices and workplace policies for HIV care: a quasi-experimental study in Jamaica, Kenya, Uganda and South Africa. Implement Sc. 2015;11(1):110. https://www.ncbi.nlm.nih.gov/pmc/articles/PMC4973110/. Accessed 16 May 2021.

\section{Figures}



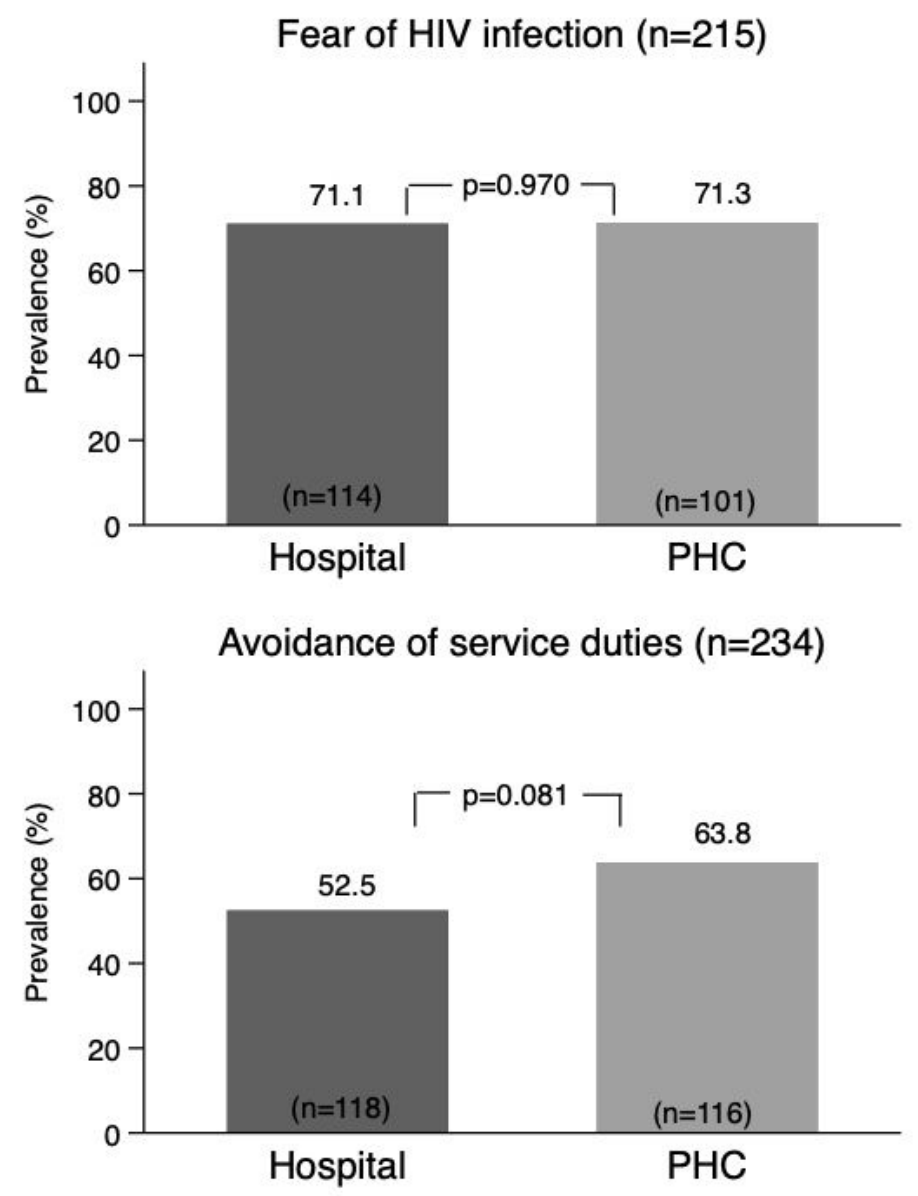

Perceived negative image of PLHIV $(n=234)$
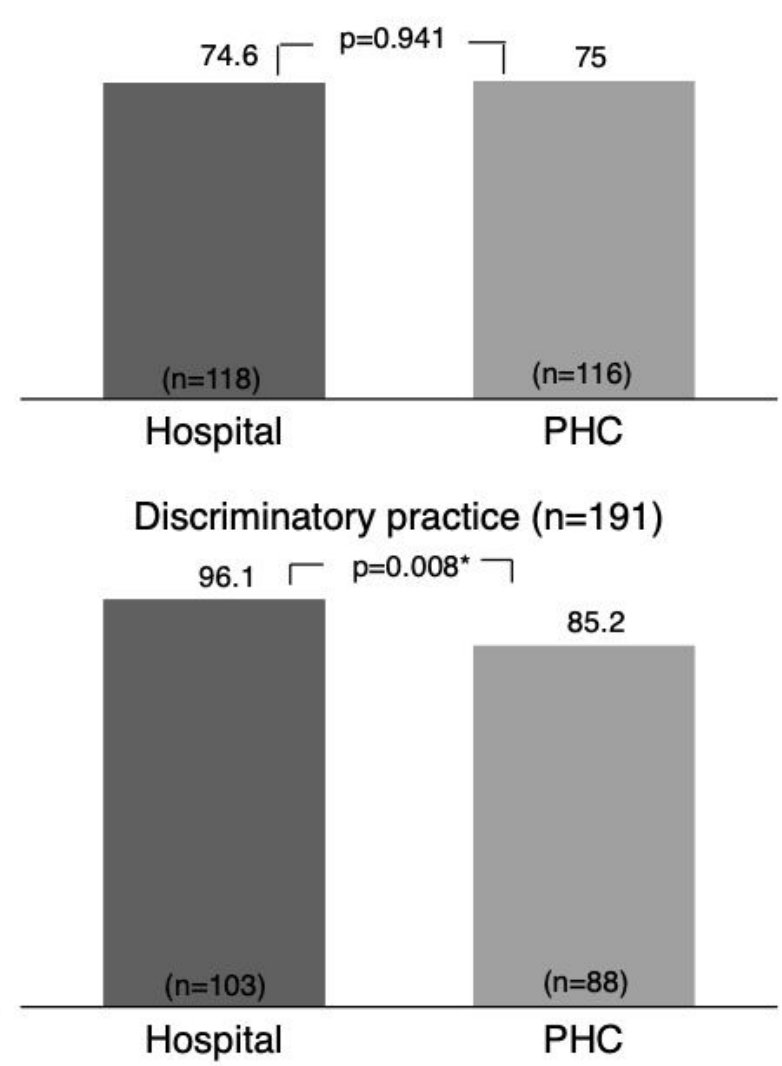

\section{Figure 1}

Prevalence of SAD indicators by facility type HIV = human immunodeficiency virus; $\mathrm{PHC}=$ primary health center; PLHIV = people living with HIV; $\mathrm{SAD}=$ stigma and discrimination. Fear of infection: how worry staff are with the prospect of HIV transmission when caring for PLHIV; perceived negative image of PLHIV: unfounded beliefs, presumptions of negative behaviors of PLHIV; avoidance of service duties: ommission, neglect to provide services for HIV key populations if such an option becomes feasible; discriminatory practice: unnecessary preventive measures taken when caring for PLHIV.

\section{Supplementary Files}

This is a list of supplementary files associated with this preprint. Click to download.

- TableA1.docx 